\title{
Coercion in psychiatric care: where are we now, what do we know, where do we go? ${ }^{\dagger}$
}

\author{
Giles Newton-Howes ${ }^{1}$
}

The Psychiatrist (2010), 34, 217-220, doi: 10.1192/pb.bp.109.027391

${ }^{1}$ Imperial College, London, UK, and Hawkes Bay District Health Board, New Zealand

Correspondence to Giles NewtonHowes (giles.newton-howes@ imperial.ac.uk)

\begin{abstract}
Summary Coercion is a subjective response to a particular intervention and has been considered an unfortunate but necessary part of the care of people with psychiatric illness. Its ethical underpinnings, evidence base and clinical implications are not commonly considered in day-to-day care; however, this requires reconsideration as the potential for an increase in coercion stretches beyond the boundaries of the hospital into the community. Much of the research that has been undertaken highlights the prevalence of coercion, the 'grey zone' between compulsory interventions and the experience of patients and patient outcomes in the light of coercion. Policy makers need to consider the evidence for interventions that increase the experience of coercion in order to reduce its impact. Clinicians need to understand the principles of procedural justice, minimise the use of legal detention and be mindful that implied consent for one intervention may lead to experiences of coercion involving linked management strategies.
\end{abstract}

Declaration of interest None.

\begin{abstract}
Medical practice has, in the modern era, steadily moved away from a paternalistic model of doctor-directed care towards a model of information sharing and autonomous decision making by patients. Most doctors and patients view this as both positive and progressive, ideally optimising the well-being of the patient. Within psychiatry this has been a factor in many of the changes in care from, for example, the asylum to the provision of predominantly community-based care and the introduction of mental health legislation in many jurisdictions to protect both patients and the public. Despite this 'progress', many patients managed by psychiatrists continue to feel coerced into a course of action they may, in fact ultimately prefer to decline, leading some to consider coercion as a necessary, if unfortunate, reality of modern community-based psychiatry.

Initiation of Mental Health Act legislation to require admission to hospital, ${ }^{1}$ locked psychiatric wards ${ }^{2}$ and the use of community treatment orders that require community patients to accept treatment ${ }^{3}$ are examples of interventions that can be seen to reduce an individual's liberty and coerce them into accepting psychiatric management. Increasingly so, the reach of these powers in psychiatry is stretching past the hospitals' doors as community treatments become more ubiquitous. This raises the importance of a reconsideration of coercion in psychiatric care: what it is, how prevalent it is, if it is supported by evidence and what, if anything, clinicians can do to reduce its sway.
\end{abstract}

†See original paper pp. 221-225, and special articles pp. 243-247, this issue.

\section{What is coercion?}

Any consideration of coercion requires a clear understanding of what coercion is, a consideration not always made in the empirical literature and debated in medical ethics. The most robust appraisal conceptualises coercion as a subjective state, within a patient, that is reached after consideration of their environment and situation. ${ }^{4,5}$ As such, coercion can be considered as a 'necessary' subjective state that arises from compulsory actions in a similar way that autonomy is the internal subjective state that is necessary to allow objective informed consent (Fig. 1).

In the empirical literature this construct is often called 'perceived coercion' in order to mark it as separate from objective interventions that may potentially increase or decrease the prevalence of coercion. This distinction is important as there is a so-called 'grey zone' that exists between interventions that may force an individual to undertake a course of action and the subjective experience of being forced or threatened into such action. ${ }^{6}$ For example, not all legally detained patients experience coercion in the action of detention, describing the process in very positive terms as making them feel safe and increasing their access to care. ${ }^{7}$ It is difficult to see how

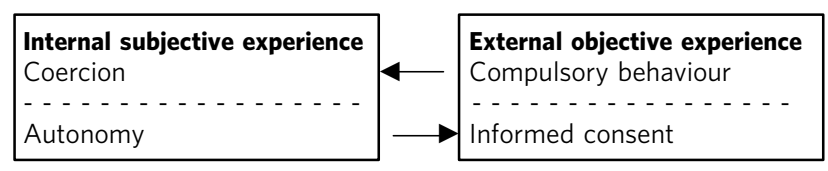

Fig 1 The relationship between coercion and compulsion, autonomy and informed consent. 
these individuals can be considered to be coerced into treatment.

\section{Historical philosophical considerations}

The concept of coercion and compulsion are not the focus of in-depth philosophical debate outside their sociopolitical ramifications in Western philosophy. Nonetheless, classical philosophers set out the necessary conditions for coercion and its potential moral implications in society. Although these arguments are not made considering medical scenarios (and some even exclude the 'mentally infirm' from their reasoning), their implications in how we conceptualise coercion and implement compulsive acts is clear.

Hobbes clarifies the necessary conditions for coercion to occur, namely one person or group in having power over another individual or group. In this environment coercion can exist. ${ }^{8}$ This view is developed by Emmanuel Kant who views coercion as philosophically in opposition to freedom. Actions that increase coercion are, however, morally acceptable when such coercion acts in the good of society as a whole. ${ }^{9}$ This position is challenged by J. S. Mill who, in his text On Liberty purports:

[An individual] cannot rightfully be compelled to do or forbear because it will be better for him to do so, because it will make him happier, because, in the opinions of others, to do so would be wise, or even right. These are good reasons for remonstrating with him, or reasoning with him, or persuading him, or entreating him, but not for compelling him, or visiting him with any evil in case he do otherwise. ${ }^{10}$

In essence, Mill is opposed to any limitation on selfgovernance; however, he does make exception in certain cases such as children and the mentally infirm on the basis that others are in a better position to ensure their good.

The importance of these historical philosophical views can be seen reflected in individual and societal practice today. In Mills' perspective the doctor fulfils the role of the person both in power and care, and the patient is potentially subject to it, whereas Kant's views are, in some respects, directly translated into most mental health legislation where the use of compulsion is morally justified on the basis of its presumed good to both the patient and society as a whole.

\section{The modern bioethical approach}

These historical concepts act as the basis for much of modern bioethics. All psychiatric interventions are designed to improve the well-being of patients who are by right considered to be able to give consent and be fully informed. This is underpinned by the ethical principle of autonomy. ${ }^{11}$ As the practice of medicine has evolved, the principle of autonomy has become one of the essential guidelines of practice, not the doctor providing the facts and figures but engaging in a dialogue that allows a patient to make an informed choice. ${ }^{12}$

By definition, coercion and compulsion sit in opposition to autonomy and informed choice ${ }^{13}$ (Fig. 1) by forcing a patient to undertake a course of action over which they have little or no control. If this is the effect of a compulsory action, the question of whether such intervention may lead to immediate harm, in opposition the principle of non-malfience ${ }^{14}$ also becomes relevant. When considering the 'harms' of coercion and compulsion it is the requirement to do 'good' that acts as a counterpoise to these bioethical concerns. In other words the consideration of any short-term coercive 'loss' is outweighed by the potential for 'good' to come in the intermediate to long term. This acts as justification for compulsory intervention that increases the likelihood of coercion. As the ability to discuss options has been put to one side and the doctor is, essentially, deciding for their patient, there is an increased burden on the professionals involved to be clear what that good is. This requires a clear understanding of the evidence both as to who might feel the effects of coercion most forcefully when a compulsory course of action is embarked on, but also the likelihood of benefit and what can be done to minimise the impact of coercion on this.

\section{Is coercion common?}

The prevalence of coercion allows us to consider whether it is rare or common and, by implication, the extent it needs to be considered by psychiatrists and policy makers. Pointprevalence rates vary considerably from as little as $10 \%$ in an American state in-patient sample ${ }^{15}$ to $100 \%$ in a small Icelandic sample. ${ }^{16}$ Systematic review provides raw prevalence rates approximating $50 \%$, primarily in psychiatric in-patient samples (unpublished data from 18 papers; details available from the author on request). The out-patient samples that provide dichotomous prevalence data in the community are of American mandated community treatment and have similar rates. ${ }^{17,18}$ Metaregression modelling confirms that legal detention is the intervention most commonly associated with the experience of lived coercion in patients, although a quarter of all patients admitted informally to hospital also experience coercive treatment (unpublished data; details available from the author on request). Cultural influences play an important role with the experience of coercion eight times as common in Nordic countries compared with the USA, with other high-income Western countries between these two extremes. The causes for this intercountry variation is unclear, however it offers the opportunity for further research to uncover which variables impact on its prevalence. What is clear from this is that coercion is commonly associated with psychiatric interventions and, although legal detention is closely associated with coercion, compulsion and coercion are empirically, as well as deductively, different constructs.

\section{Who experiences coercion most?}

If coercion is common, identification of who is most likely to experience coercion allows clinicians to focus their attention on reducing coercion in target populations. Other than legal compulsion, it is not immediately obvious who is most at risk of coercion in psychiatric care.

Basic demographic data is contradictory. For example, Bindman and colleagues found positive correlations between increasing age and Black and minority ethnicity, suggesting in England at least elderly Black and ethnic minority individuals were potentially at greatest risk of being coerced. ${ }^{19}$ Two Nordic studies, however, found contradictory 
correlations regarding age and gender, ${ }^{20,21}$ with a major American study ${ }^{22}$ and a New Zealand study ${ }^{23}$ finding Black and minority ethnicity to be protective. Similarly, contradictory evidence exists for psychopathology, ${ }^{3,17,20,24}$ satisfaction with care ${ }^{21,25}$ and global functioning. ${ }^{25,26}$

Social adjustment gives a better guide, with those functioning well in society most unhappy with a loss of autonomy. It is perhaps unsurprising that those who are better adjusted to living in the community feel it to be particularly intrusive to be admitted to hospital ${ }^{24}$ or required to be mandated to out-patient treatment, ${ }^{17}$ although this insight does not reflect outcomes if such coercive interventions were not implemented.

If demographic, symptom and functioning data provide only weak associative data to identify those most likely to experience psychiatric interventions' as coercive, what other measure might help to guide clinical practice? Four studies have identified interactive processes, broadly related to 'being heard' that are important in the patients' experience of coercion. ${ }^{23,27-29}$ Using different measures, these studies all show that patients' who experienced professional staff as listening to their views as feeling less coerced, even if involved in legally mandated treatment. Qualitative research mirrors this finding. These studies highlight that loss of a voice, ${ }^{30}$ disrespect by professional staff $^{31}$ and violation of integrity ${ }^{32}$ lead to feelings of coercion. These papers are interesting as they do not focus on a particular intervention, rather the patients' experience. It would seem as if the experience of coercion is at least as related to the interpersonal experience of the patient in their relationship with those delivering care rather as it is to particular psychiatric interventions.

\section{Do 'coercive interventions' work?}

If the experience of coercion is common, as it appears to be, and we are unable to reliably assess who is most coerced, positive outcomes become the justification for compulsory actions leading to coercion. These outcome data are, unfortunately, scarce and too heterogeneous to combine in any meaningful way.

The authors of the two randomised controlled trials of community treatment orders, both in the USA, suggest such interventions, clearly associated with coercion, improve outcomes in multiple domains ${ }^{18,33-35}$ although a comprehensive Cochrane review of essentially the same data was less optimistic. ${ }^{36}$ It suggests that these same trials showed little improvement in readmissions, social functioning, mental state or quality of life. From a risk perspective the Cochrane review suggests 238 people would need to be under mandated community treatment to prevent a single arrest - hardly an effective intervention.

It is equally difficult to find evidence that compulsory hospital admission, also associated with coercion, leads to improved outcomes. In a large British sample, followed for 12 months, Priebe and colleagues did not find any relationship between outcomes and coercion, although satisfaction with the admission process did appear to be predictive of readmission. ${ }^{37}$ This finding mirrors the quantitative and qualitative findings of the importance of the interpersonal experience during compulsory interventions.

\section{Implications and limitations}

What does all this mean? From a sociopolitical perspective, interventions that increase coercion such as courtmandated treatment appear to be becoming more prevalent despite philosophical and ethical concerns and a lack of evidence that support their use. Major structural change to psychiatric care without any evidence to support its implementation is, unfortunately, not uncommon. ${ }^{38}$ Nor does it seem likely that interventions such as mandated community treatments and detention in hospital will disappear overnight. From a pragmatic perspective the question is then how to practice and research psychiatry within the current social and legal framework.

The evidence to date emphasises the importance of the attitudes of mental health workers towards their patients as a key factor that may be amenable to change. A combination of listening and respecting the patient's view is likely to minimise any experience of coercion, even if the outcome is compulsory treatment. Although mental health professionals have worked hard to minimise the negative attitudes towards mental health in the community, ${ }^{39,40}$ these negative attitudes remain present even within services, ${ }^{41}$ suggesting a need to remain focused on the interactions of all clinicians. The importance of this approach is supported by the work of the MacArthur Foundation who coined the phrase 'procedural justice, ${ }^{42}$ to express a similar view. For inpatients, the fact that one in four voluntary patients experience coercion suggests consideration of the consent process for intervention in hospital needs to be reviewed, and implied consent in this patient group may not be sufficient. The clear correlation between legal compulsion and coercion, without comparable evidence of improved outcome (or improved community safety) would recommend any course of action that reduces compulsory status as beneficial to individual patients.

The key factors for psychiatric practice when considering coercion include the following:

- the philosophical and ethic basis for compulsory treatments leading to coercion is the improved freedoms to the patient and beneficence;

- half of all in-patients experience coercion and the rates are probably similar in the community;

- consent to voluntary admission to hospital does not imply consent to all procedures in hospital;

- legal detention increases coercion with mixed evidence of it improving outcomes;

- there is very limited evidence that legally mandated community treatment improves patient outcomes or the safety of the public.

On a broader scale the need to continue to understand coercion, separate from compulsory actions, remains important and peer-reviewed tools are available to improve the methodological robustness of research. ${ }^{43}$ The social impact of coercion needs to be considered by public policy and law makers to ensure interventions are not developed that work against the destigmatisation of mental health and do not further alienate a vulnerable group of people. When potentially coercive cultural interventions are implemented, examination of their impact is essential. 
Finally, all mental health workers need to bear in mind the difficulties struggling with a mental illness can bring and be reflective about how they can work with individuals to maximise the chances of a positive outcome from a patient perspective, and to this end minimise the threat of coercion in day-to-day care.

\section{About the author}

Giles Newton-Howes (BA, BSc, MBChB, MRCPsych, FANZRCP (Affiliate)) is an honorary senior lecturer in the Department of Psychological Medicine, Imperial College London, UK, and also a consultant psychiatrist at Hawkes Bay District Health Board, Napier, New Zealand.

\section{References}

1 Katsakou C, Priebe S. Outcome of involuntary hospital admission - a review. Acta Psychiatr Scand 2006; 114: 232-41.

2 Haglund K, Von Essen L. Locked entrance doors at psychiatric wards advantages and disadvantages according to voluntarily admitted patients. Nord J Psychiatry 2005; 59: 511-5.

3 Monahan J, Bonnie R, Appelbaum $\mathrm{P}$, Hyde $\mathrm{P}$, Steadman $\mathrm{H}$, Swartz M Mandated community treatment: beyond outpatient commitment. Psychiatr Serv 2001; 52: 1198-205.

4 Rhodes M. The nature of coercion. J Value Inquiry 2000; 34: 369-81.

5 Szmulker G, Applebaum P. Treatment pressures, leverage, coercion and compulsion in mental health care. J Ment Health 2008; 17: 233-44.

6 Eriksson K, Westrin C-G. Coercive measures in psychiatric care. Acta Psychiatr Scand 1995; 92: 225-30.

7 Gibbs A, Dawson J, Mullen R. How patients in New Zealand view community treatment orders. J Ment Health 2005; 14: 357-68.

8 Hobbes T. Chapter XIV: Of the first and second naturall lawes, and of contracts. In The Leviathan. Andrew Crooke and William Crooke, 1651 (http://www.gutenberg.org/dirs/etext02/Ivthn10.txt).

9 Kant I. The Metaphysics of Morals (trans. M Gregor). Cambridge University Press, 1996 (original work published 1797).

10 Mill JS. Chapter I: Introductory. In On Liberty. Longman, Roberts \& Green, 1859 (http://www.utilitarianism.com/ol/one.html).

11 Beauchamp T, Childress J. The Principles of Biomedical Ethics. Oxford University Press, 2001.

12 Quill T, Brody $\mathrm{H}$. Physician recommendations and patient autonomy: finding a balance between physician power and patient choice. Ann Intern Med 1996; 125: 763-9.

13 Compact Oxford English Dictionary. Oxford University Press, 2008 (http://www.askoxford.com/concise_oed/coerce?view=uk)

14 The Hippocratic Oath (trans. M North): para 3. National Library of Medicine, 2002 (http://www.nlm.nih.gov/hmd/greek/ greek_oath.html).

15 Hoge S, Lidz C, Eissenberg M, Gardner W, Monahan J, Mulvey E, et al. Perception of coercion in the admission of voluntary and involuntary psychiatric patients. Int J Law Psychiatry 1997; 20: 167-81.

16 Kjellin L, Hoyer G, Engberg M, Kaltiala-Heino R, Sigurjonsdottirl M. Differences in perceived coercion at admission to psychiatric hospitals in Nordic countries. Soc Psychiatry Psychiatr Epidemiol 2006; 41: 241-7.

17 Link B, Castille D, Stuber J. Stigma and coercion I the context of outpatient treatment for people with mental illness. Soc Sci Med 2008; 67: 409-19.

18 Swartz M, Wagner R, Swanson J, Hiday $V$, Burns B. The perceived coerciveness of involuntary outpatient commitment: findings from an experimental study. J Am Acad Psychiatry Law 2002; 30: 207-17.

19 Bindman J, Reid Y, Szmukler G, Tiller J, Thornicroft G, Leese M Perceived coercion at admission to psychiatric hospital and engagement with follow up. Soc Psychiatry Psychiatr Epidemiol 2005; 40: 160-6.

20 Poulsen $H$. Perceived coercion among committed, detained and voluntary patients. Int J Law Psychiatry 1999; 22: 167-75.
21 Iversen K, Hoyer G, Sexton H. Coercion and patient satisfaction on psychiatric acute wards. Int J Law Psychiatry 2007; 30: 504-11.

22 Lidz C, Hoge S, Gardner W, Bennett NS, Monahan, J, Mulvey E, et al. Perceived coercion in mental hospital admission. Arch Gen Psychiatry 1995; 52: 1034-9.

23 McKenna AB, Simpson A, Coverdale J. Patients' perceptions of coercion on admission to forensic psychiatric hospital: a comparison study. Int $J$ Law Psychiatry 2003; 26: 355-72.

24 Iversen K, Hoyer G, Sexton H, Gronli O. Perceived coercion among patients admitted to acute wards in Norway. Nord J Psychiatry 2002; 56: 433-9.

25 Svensson B, Hansson L. Pateints satisfaction with inpatient psychiatric care. Acta Psychiatr Scand 1994; 90: 379-84.

26 Nicholson R, Ekenstam C, Norwood S. Coercion and the outcome of psychiatric hospitalization. Int J Law Psychiatry 1996; 19: 201-17.

27 Lidz C, Mulvey E, Hoge S, Kirsch BC, Monahan J, Eisenberg, M, et al. Factual sources of psychiatric patients' perceptions of coercion in the hospital admission process. Am J Psychiatry 1998; 155: 1254-60.

28 Shannon P. Coercion and compulsory hospitalization, some patient attitudes. Med J Aust 1976; 2: 798-800.

29 Sorgaard K. Satisfaction and coercion among voluntary, persuaded/ pressured and committed patients in acute psychiatric treatment. Scand J Caring Sci 2007; 21: 214-9.

30 Olofsson B, Norberg A. Experiences of coercion in psychiatric care as narrated by patients, nurses and physicians. J Adv Nurs 2001; 33: 89-97.

31 Olofessen B, Jacobsson L. A plea for respect: involuntary hospitalized psychiatric patients' narratives about being subjected to coercion. J Psychiatr Ment Health Nurs 2001; 8: 357-66.

32 Haglund K, Von Knorring L, Von Essen L. Forced medication in psychiatric care: patient experiences and nurse perceptions. J Psychiatr Ment Health Nurs 2003; 10: 65-72.

33 Rain S, Steadman $\mathrm{H}$, Robbins $\mathrm{P}$. Perceived coercion and treatment adherence in an outpatient commitment program. Psych Serv 2003; 54 399-401.

34 Steadman H, Gounis K, Dennis D, Hopper K, Roche B, Swartz M, et al. Assessing the New York City involuntary outpatient commitment pilot program. Psych Serv 2001; 52: 330-6.

35 Swartz M, Swanson J, Wagner R, Burns B, Hiday V, Borum R. Can involuntary outpatient commitment reduce hospital recidivism? Findings from a randomized trial with severely mentally ill individuals. Am J Psychiatry 1999; 156: 1968-75.

36 Kisley S, Campbell L, Preston N. Compulsory community and involuntary outpatient treatment for people with severe mental disorders. Cochrane Database Syst Rev, 2005; issue 3: CD004408.

37 Priebe S, Katasakou C, Amos T, Leese M, Morriss R, Rose, D, et al. Patients' views and readmission 1 year after involuntary hospitalisation. Br J Psychiatry 2009; 194: 49-54.

38 Malone D, Marriott S, Newton-Howes G, Simmonds S, Tyrer P. Community mental health teams (CMHTs) for people with severe mental illnesses and disordered personality. Cochrane Database Syst Rev, 2007; issue 3: CD000270.

39 Crisp AH, Cowan L, Hart D. The College's Anti-Stigma Campaign, 19982003. A shortened version of the concluding report. Psychiatr Bull 2004; 28: $133-6$.

40 Ministry of Health. Building on Strengths: A New Approach to Promoting Mental Health in New Zealand/Aotearoa. Ministry of Health, 2002 (http://www.moh.govt.nz/moh.nsf/238fd5fb4fd051844c256669006aed 57/0ac9595e4c7f4d63cc256d9d00716367).

41 Newton-Howes G, Tyrer P, Weaver T. The attitudes of mental health workers towards patients with personality disorders in community mental health settings. Aust N Z J Psychiatry 2008; 42: 572-7.

42 Lidz C, Mulvey E, Hoge S, Kirsch B, Monahan J, Bennett N, et al. Sources of coercive behaviors in psychiatric admissions. Acta Psychiatr Scand 2000; 101: 73-9.

43 Gardner W, Hoge S, Bennett N, Roth L, Lidz C, Monahan J, et al. Two scales for measuring patients' perceptions of coercion during hospital admission. Behav Sci Law 1993; 20: 307-21. 